\title{
Epidemiology of spinal cord injuries: a reflection of changes in South African society
}

\author{
Cathy Hart* BSc Physio (Wits), Evan Williams MB ChB (Pret), FCS (Orth) SA \\ Natalspruit Hospital, Transvaal, Republic of South Africa and Department of \\ Orthopaedic Surgery, University of the Witwatersrand, Johannesburg, Republic of South \\ Africa
}

\begin{abstract}
The records of all patients (492 males and 124 females) admitted into a spinal rehabilitation programme over a period of 6 years were reviewed. Most of the patients were in the age group 20-29 years and trauma accounted for $89 \%$ of all spinal cord lesions. Gunshot injuries were the commonest $(36 \%)$, followed by injuries related to motor vehicle accidents (MVA) $(25 \%)$, stab wounds $(20 \%)$ and falls from heights $(2.4 \%)$. Aetiological patterns changed over the 6 year period covered: gunshot injuries increased markedly and stab wounds decreased in number. The records of a medico-legal laboratory in the same geographic region revealed the same trend. Neurological recovery rates were better in patients with stab wounds and nontraumatic lesions than in those with MVArelated injuries and gunshot wounds. When compared to similar studies from other countries, our results show a disproportionately high incidence of violent injuries, particularly gunshot wounds, in South African plegic patients. We concluded that the recent sociopolitical changes and especially the general escalation of violence in the country, is reflected in the observed changes in the epidemiology of spinal cord injuries
\end{abstract}

Keywords: epidemiology; spinal cord injury; South Africa.

\section{Introduction}

Spinal cord injuries (SCI) remain one of the most serious lesions suffered by modern man, often leading to permanent paralysis. These injuries are largely preventable. ${ }^{1}$ Previous analyses have pointed to motor vehicle accidents as the most common cause of $\mathrm{SCI}^{2-7}$ We reviewed the aetiology of injuries in patients who had undergone rehabilitation in the Natalspruit Hospital Spinal Rehabilitation Unit over a 6 year period.

Natalspruit Hospital is a regional health facility situated $30 \mathrm{~km}$ south-east of Johannesburg. The spinal rehabilitation unit serves the Southern Transvaal region and patients admitted there are predominantly black. The unit has 44 beds and is managed by physiotherapists, occupational therapists, nursing staff and a social worker.

*Correspondence: 22 The Willows, Field Close, Bedfordview 2008, Republic of South Africa.
Medical staff are not integrated in the unit, but a neurosurgeon and orthopaedic surgeons advise the staff, while doctors with other surgical and medical specialties are also available for consultation when necessary. The rehabilitation programme is offered to patients whose general clinical condition has already been stabilised and who are ready to be mobilised. Surgical stabilisation of vertebral lesions is usually performed before patients are admitted to the unit; only rarely do the neurosurgeon or orthopaedic surgeons operate on patients after their admission into the unit.

\section{Materials and methods}

We reviewed the records of all patients who had undergone rehabilitation during the period January 1988 to December 1993 . We compared patients' ages, time at which the 
injury occurred, aetiology of SCI, general clinical status, complications, recovery and functional ability at the time of discharge from the unit. The records of a medico-legal laboratory in the region (Braamfontein, Johannesburg) were reviewed and the changes in the relative occurrence of gunshot wounds and stab wounds found at postmortem were compared to the statistics of cases in the spinal unit.

\section{Results}

\section{Age distribution}

Records of 616 cases were assessed. There were $492(80 \%)$ male and $124(20 \%)$ female patients. Fig 1 shows the relation between age, gender and number of cases in each group. Males between 15 and 40 years of age made up the majority of the patients in this study, with the age group 20-24 years accounting for $23 \%$ and the age group 25-29 years for another $23 \%$ of the total number.

\section{Aetiological classification}

Trauma accounted for $89 \%$ of SCI's. Aetiology could be divided into five groups (see Fig 2): gunshot injuries predominated, accounting for 219 cases $(36 \%)$. Motor vehicle accidents (MVA) accounted for 152 cases $(25 \%)$, stab wounds for 122 cases $(20 \%)$, falls from heights for 15 cases $(2.4 \%)$ and all other causes for the remaining 38 cases $(5.6 \%)$. Acts of violence resulted in 341 SCI's $(55 \%)$ in this group of patients. Nontraumatic pathology, mostly spinal tuberculosis, was present in only 70 cases $(11 \%)$.

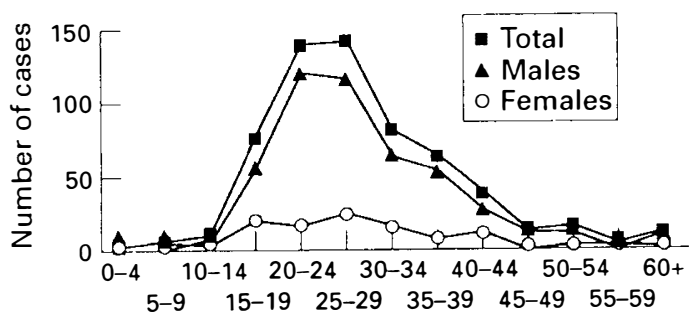

Age group

Figure 1 Age distribution of patients admitted to the spinal rehabilitation unit, 1988-1992.

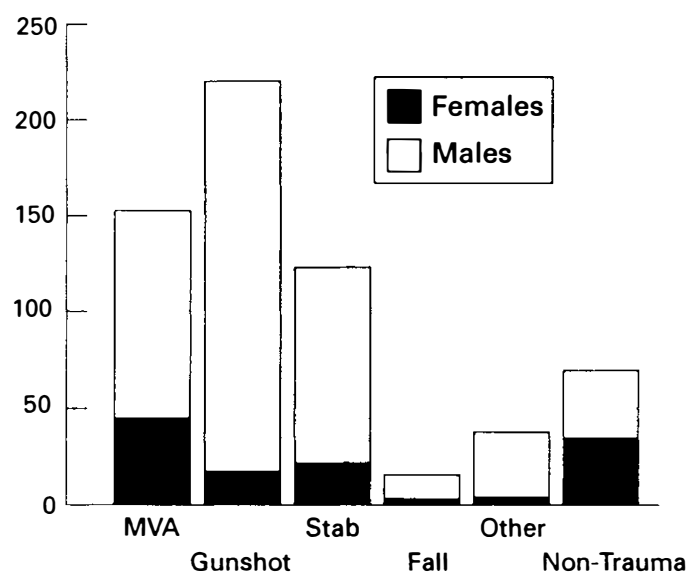

Figure 2 Distribution of patients according to aetiology of SCI.

\section{Gender differences}

Aetiological patterns differed between the genders: in male patients, gunshot injuries were commonest $(41 \%)$, followed by MVA $(22 \%)$ and stab-wounds $(20 \%)$; while in female patients, MVA caused the majority of SCI's $(35 \%)$, followed by stab wounds $(18 \%)$ and gunshot injuries $(14 \%)$. In the group of nontraumatic SCIs, the sex ratio was equal.

\section{Temporal changes in aetiological patterns} Aetiological patterns changed in the 6 year period covered by this study (Table I). There was a marked increase in the prevalence of gunshot injuries and a decrease in the number of stab wounds among patients in the unit. We reviewed the records of a medico-legal laboratory in the same geographical region and found a similar trend in the aetiology of fatalities in the same 6 year period (see discussion below, Figure 3 and Table III.)

\section{Neurological deficit}

Information on patients' initial neurological status (before transfer to our unit) was not always available. At the time of admission, $75 \%$ of the patients were paraplegic and $25 \%$ tetraplegic. In 155 cases $(25 \%)$ the cervical spine was affected, in 135 cases $(23 \%)$ the upper thoracic spine, in 249 cases 
Table I Aetiology of SCIs over a 6 year period (figures represent number of patients in each subgroup)

\begin{tabular}{lccccccc}
\hline & MVA & Gunshot & Stab & Falls & Other & Non-trauma & Total \\
\hline 1988 & 19 & 24 & 29 & 0 & 10 & 15 & 97 \\
1989 & 30 & 15 & 24 & 2 & 1 & 13 & 85 \\
1990 & 32 & 36 & 23 & 4 & 8 & 13 & 116 \\
1991 & 19 & 34 & 20 & 3 & 11 & 10 & 97 \\
1992 & 30 & 56 & 10 & 1 & 4 & 11 & 112 \\
1993 & 22 & 54 & 16 & 5 & 4 & 8 & 109 \\
Total & 152 & 219 & 122 & 15 & 38 & 70 & 616 \\
\hline
\end{tabular}

$(40 \%)$ the lower thoracic and in 74 cases $(12 \%)$ the lumbar spine. In 404 cases $(66 \%)$ the neurological deficit was total and in the remaining 212 cases $(34 \%)$ the lesion was incomplete.

\section{Complications}

The commonest complications were pressure sores, which were present in 47 cases at the time of arrival in the unit and developed in a further 23 patients during the rehabilitation programme. Severe spasticity occurred in 43 cases $(7 \%)$, urological complications in 18 cases $(3 \%)$ and debilitating pain in 12 $(2 \%)$. The overall mortality rate was $7.4 \%$. As autopsies were not performed routinely, analysis of the causes of death could not be included in this study.

\section{Recovery}

The Frankel classification was used to assess neurological recovery. ${ }^{8}$ Recovery was defined as improvement from Frankel group $\mathrm{A}, \mathrm{B}$ or $\mathrm{C}$ to Frankel group $\mathrm{D}$ or $\mathrm{E}$ during the period of rehabilitation. 261 patients $(42 \%)$ showed recovery; of these, 76 had had stab wounds, 37 nontraumatic lesions, 53 MVA-related injuries and 68 gunshot injuries. This means that stab wounds and nontraumatic lesions had better rates of recovery $(68.4 \%$ and $56.9 \%$, respectively) than MVA-related injuries and gunshot wounds $(35.5 \%$ and $31 \%)$.

\section{Functional capacity}

The duration of patients' stay in the unit ranged from 3-6 months. At the time of discharge, 245 patients $(40 \%)$ could walk with or without walking appliances, 203 (33\%) moved about in wheelchairs, but were also able to walk with calipers and 167 $(27 \%)$ were permanently confined to their wheelchairs.

\section{Discussion}

In our study, the male:female ratio was $4: 1$; this correlates with the findings of research in other countries. ${ }^{2-5}$ The age distribution of our patients was also similar to that found in other surveys. ${ }^{2-5}$ The age group $15-39$ years comprised the largest proportion of our cases, namely $82 \%$. The aetiology of injuries encountered in this study is compared to that of other studies in Table II. The international literature on spinal cord injuries reports motor vehicle accidents and falls from heights as the most common causes of these lesions. In our study, acts of violence, rather than accidents, accounted for the majority of injuries: $36 \%$ of our patients had suffered gunshot injuries and a further $20 \%$ stab wounds.

Table II Aetiology of SCIs reported in different countries (expressed as percentages)

\begin{tabular}{|c|c|c|c|c|}
\hline & MVA & Gunshot & Stabs & Falls \\
\hline South Africa & 25.0 & 36.0 & 20.0 & 2.4 \\
\hline Spain $^{3}$ & 52.2 & 3.2 & - & 27.4 \\
\hline Turkey² & 35.4 & 21.95 & - & 29.5 \\
\hline France $^{4}$ & 50.7 & 2.0 & - & 31.5 \\
\hline Australia $^{2}$ & 48.7 & 5.8 & - & 26.6 \\
\hline USA $^{1,4,7}$ & 42.8 & 12.3 & - & 19.2 \\
\hline England $^{2}$ & 46.8 & 0 & - & 25.7 \\
\hline Nigeria $^{5}$ & 75.0 & - & - & 23.0 \\
\hline
\end{tabular}




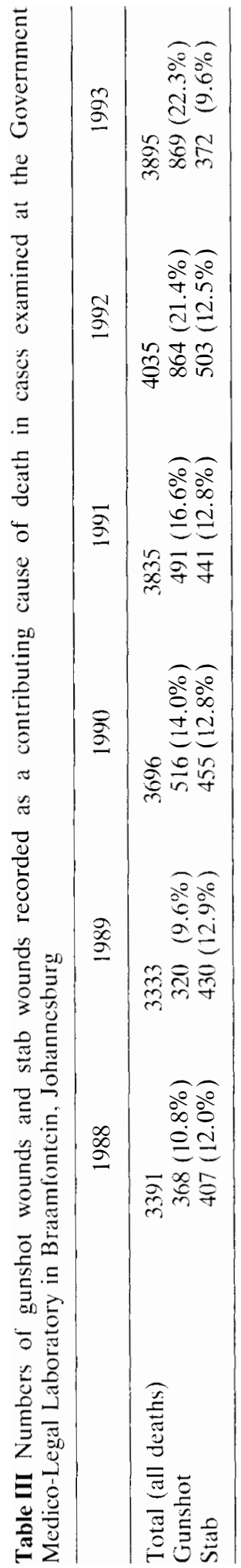

The author has worked in close proximity to the violence in the East Rand townships. This region has been the scene of fluctuant but intense and prolonged violence over the past 3 years. Natalspruit Hospital featured on national newscasts on several occasions, not only for its role in the emergency management of victims of the turmoil in the region, but also the several occasions when the hospital grounds became a haven for large numbers of women and children, who would gather there to seek refuge from groups of armed men fighting in the streets of the adjacent townships.

The distribution of aetiology of SCIs over the 6 year period covered in this study shows marked changes: there was an increase in the number of gunshot victims in the unit ( $21 \%$ in 1988 compared to $50 \%$ in 1993 ) and in the same period, stab wounds decreased from $30 \%$ to $15 \%$. We found a similar trend in the causes of death recorded in medicolegal mortuaries in the region, suggesting that our records reflect changes in the behaviour of the community from which our patients are referred (Fig 3). This increased prevalence of gunshot injuries can probably be ascribed to three interrelated factors: (a) increased levels of violence, both political and otherwise, (b) the accompanying release into the community of caches of unlicensed firearms, most of which were originally intended for political struggle and (c) the fact that stab wounds are less likely to damage the spinal cord in its bony canal than bullets, against which the vertebrae provide scant protection.

Violence has dominated the news in South Africa in the recent past. The turmoil following recent political developments is reflected in the unprecedented dimensions violence reached after 1990, which has affected all sectors of the black community. ${ }^{11}$ Aggression in society manifested not only in politically motivated violence, but has been accompanied by an increase in the prevalence of crime, increased use of military weapons in common criminal events, increased domestic violence and sexual attacks. ${ }^{9}$ We believe that the same phenomena are reflected in the changes we have observed in our unit.

In South Africa, there is no programme 

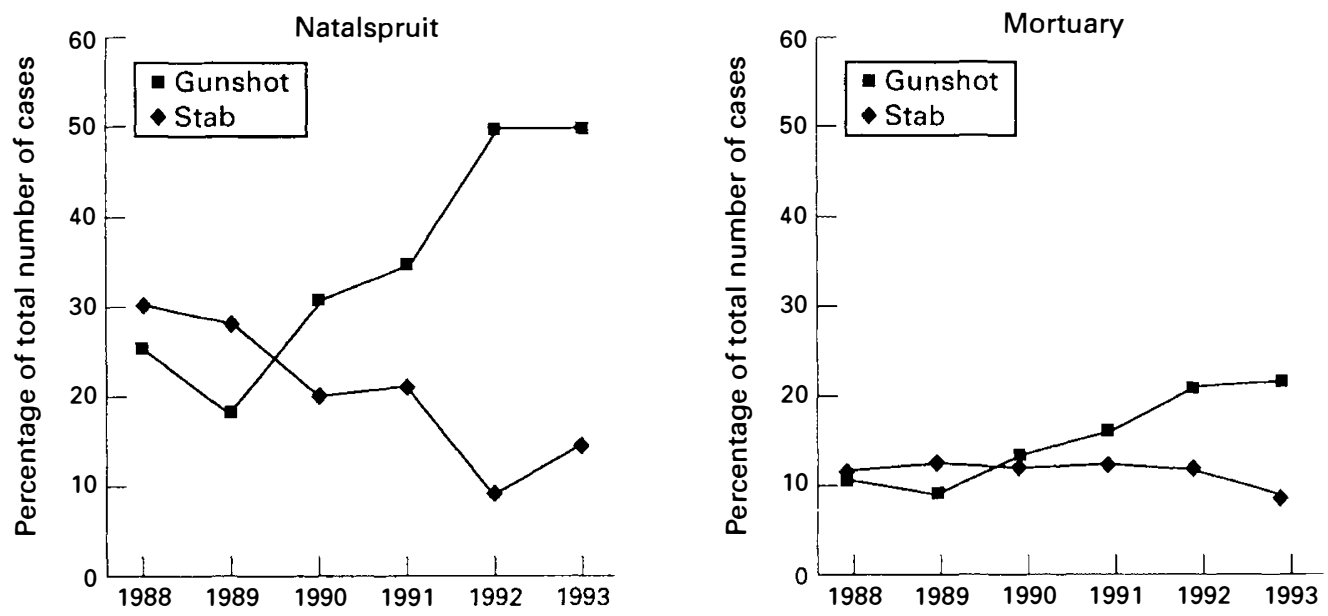

Figure 3 Changes in the relative occurrence of gunshot injuries and stab wounds in cases managed in the Natalspruit Spinal Rehabilitation Unit (left), compared to the cases seen in the Braamfontein medico-legal mortuary (right) during the period 1988 to 1993. Figures are presented as percentages of the total number of cases seen in each year. The trend towards a lower incidence in the number of stab wounds and a marked increase in the number of gunshot injuries is similar.

aimed specifically at the prevention of SCI's. Such a programme was set up in Michigan, USA, when it became evident that victims of violent acts in a local spinal rehabilitation institute were increasing in numbers $(38 \%$ of their cases, compared to their National Model Systems statistics of 14\%). ${ }^{10}$ South African medical services have to function under increasing financial restraints and the current emphasis is on primary health care. We expect that improvement in such expensive and specialised programs as the treatment of spinal cord injuries will remain a low priority.

\section{Conclusion}

The epidemiology of spinal cord injuries in South Africa reflects the social and political environment. Changes in behaviour will have a more profound effect on disability statistics than treatment of injuries. There are no easy solutions to the problems facing the plegic patient. While we can provide essential rehabilitation, these patients also need ongoing help from their families and community-based structures. Patients now have to return to an increasingly disorganised and turbulent community in which they find little support. Our focus should be on the community outside the hospital; the same violence that causes spinal cord injuries also hampers reincorporation of the disabled into society. We can play an important role in increasing public awareness of the possible long term results of the pattern of behaviour South Africa has recently encountered. We expect that the changes brought about by the recent elections will have a visible effect on the admission statistics in our unit.

\section{References}

1 Griffin MR, Opitz JL, Kurland LT et al (1985) Traumatic spinal cord injury in Minnesota, 1935-1981. Am J Epidemiol 12 1: 884-952.

2 Dincer F, Oflazor A, Beyazova M et al (1992) Traumatic spinal cord injuries in Turkey. Paraplegia 30: 641-646.

3 Garcia-Reneses J, Herruzo-Cabrera R, Martinez-Moreno M (1991) Epidemiology study of spinal cord injury in Spain 1984-1985. Paraplegia 29: 180-190. 
4 Minaire P, Castanier M, Girard R et al (1978) Epidemiology of spinal cord injury in the Rhone-Alpes region, France 1970-1975.Paraplegia 16: 76-78.

5 Iwegbu CG (1983) Traumatic paraplegia in Zaire, Nigeria: the case for a centre for injuries of the spine. Paraplegia 21: 81-85.

6 Shrosbree RD (1978) Spinal cord injuries as a result of motorcycle accidents. Paraplegia 16: 102-112.

7 Murray PK, Kusior MF (1984) Epidemiology of nontraumatic and traumatic spinal cord injury. Arch Phys Med Rehabil 65: 634.

8 Frankel HL, Hancock DO, Hyslop G et al (1969-1970) Value of postural reduction in initial management of closed injuries of the spine with paraplegia and tetraplegia: Part I. Paraplegia 7: 179-192.

9 Eagle G (1992) Violence in South Africa: on the increase in the 1990s. Critical Health 41: 6-7.

10 Weingarten SI, Graham PM (1991) Targeting teenagers in a spinal cord injury prevention program. Paraplegia 29: 65-69.

11 Moodley SA (1993) Gunshot injuries in children. Paper presented at the 39th Congress of the South African Orthopaedic Association, 9 September 1993. 